\title{
SOBRE EL CONTROL \\ DE LA REFORMA \\ CONSTITUCIONAL \\ (con especial referencia \\ a la experiencia jurídica peruana)*
}

\author{
POR \\ DOMINGO GARCÍA BELAUNDE
}

1. PRELIMINAR

El problema de la reforma constitucional apareció por vez primera en el artículo $\mathrm{V}$ de la Constitución de los Estados Unidos de América de 1787 todavía vigente, y desde entonces ha tomado diversos caminos y ha adoptado variados matices en los textos constitucionales sancionados en Europa primero, y en América Latina después. Extendido más adelante a las nuevas repúblicas nacidas después de la Primera Guerra Mundial, de la Segunda y también de las que han aparecido con motivo del proceso de descolonización iniciado en la década de 1960. Y de la posterior emancipación política de las antiguas democracias del Este, que estuvieron en cierto sentido bajo el dominio de la antigua URSS.

* Ponencia presentada en el Congreso Internacional «Reforma de la Constitución y control de la constitucionalidad" (Pontificia Universidad Javeriana, Bogotá, 14-18 de junio de 2005). 
Lo primero que se nos presenta es cómo denominarla, pues hay varias alternativas dependiendo en gran parte de los usos y costumbres de cada país o de los respectivos significados en cada lengua. Asi, en los Estados Unidos se usa la palabra "enmienda" tanto en el ámbito federal como en el de los Estados (si bien esto con matices), y referido básicamente al cambio, adición o modificación de un texto constitucional preexistente. Si bien en el idioma inglés existen las palabras "reforma" y "revisión" y usándolas se puede entender hacia donde van ellas, la práctica política, jurisprudencial y doctrinaria ha privilegiado la palabra "enmienda" (amendment) en lugar de las otras. Asi, el Black's Law Dictionary define la "enmienda" como "un cambio, generalmente para mejorar", "cambio", "modificación»; "reforma» como "corregir, rectificar, enmendar, remodelar» y "revisión" como "re-examinar» para corregir o mejorar. Es decir, sin llegar a la sinonimia, tienen significados comunes o similares.

En otros países como es el caso de Italia, se prefiere la palabra «revisión» (revisione) como puede verse en el Dizionario costituzionale editado por Michele Ainis (Editori Laterza, Roma 2000). La manualística francesa emplea el concepto "révision constitutionelle». Y en lo relacionado con los países de habla castellana incluido España, se prefiere la palabra "reforma».

Pero lo que cabe advertir en estos tres usos, es decir, enmienda, revisión y reforma, es que todos apuntan a lo mismo: una modificación a un texto preexistente. $Y$ además, según los casos, puede ser total o parcial, dependiendo de diversas posturas doctrinarias u opciones normativas (así la Constitución puede adoptar una tesis permisiva amplia o simplemente señalar que apartados normativos no son susceptibles de revisión, reforma o enmienda... O incluso permitir modificaciones totales agravando el proceso para determinados artículos).

Sin embargo, hay situaciones en las cuales se han introducido diferencias o variantes, como en la Constitución venezolana de 1961, reiterado en la vigente Constitución bolivariana de 1999, en donde se dan don figuras: la "enmienda" que significa un cambio en aspectos cuantitativamente pequeños y no trascendentes, y la "reforma" que afecta a aspectos importantes, pero ninguna de ellas puede hacer un cambio total, lo que se reserva a la Asamblea Constituyente prevista en la misma Constitución. Se trata, como es de verse, de una opción del legislador constituyente de crear una diferencia entre dos conceptos estableciendo las notas que caracterizan a cada uno de ellos y que es absolutamente convencional, pues no tiene ningún asidero lingüístico, ni doctrinario ni histórico. Esto se puede apreciar por ejemplo, en el caso 
del Brasil, donde tradicionalmente se han usado las dos variantes, pero que finalmente la vigente Constitución de 1988 ha empleado el concepto de "enmienda", que a su vez puede ser total o parcial.

En síntesis, bajo diversos nombres se esconde una sola realidad, ya que las palabras no difieren mayormente en su significado, $y$, si se introducen diferencias entre ellas, es solamente en el ámbito de la dogmática, como una clara opción política, pero no por nada que sea más profundo de lo que ella misma significa.

Esto es lo que debemos tener presente para lo que sigue después.

\section{EL SENTIDO DE UNA REFORMA}

Lo que está detrás de toda reforma constitucional es simplemente la vida o la supervivencia de un orden normativo; esto es, el eterno problema entre "tiempo" y "derecho». Pues como bien señaló Roscoe Pound hace varias décadas, el Derecho debe ser estable, pero tampoco puede permanecer inamovible. Debe ser estable, pues la fijeza apunta a la seguridad jurídica que es uno de los valores del Derecho, pues los cambios y las agitaciones continuas no son convenientes para la vida del Estado. Pero tampoco puede ser eterno, porque el tiempo también pasa por las instituciones y a veces los cambios son necesarios a fin de poder mantener las cosas, por lo menos en su sentido esencial.

Esto fue visto muy claramente al momento de nacer el constitucionalismo moderno en los Estados Unidos, cuando Jefferson señaló —en frase feliz que luego otros han repetido- que las generaciones presentes no pueden atar de por vida a las generaciones futuras, ya que existiría de esta manera una especie de dictadura de los muertos sobre los vivos (entre otras, la carta de Jefferson a John Cartwright de 5 de junio de 1824). De ahí la necesidad de hacer un texto estable que tienda a durar, pero con mecanismos de cambios que permitan su adecuación a los tiempos y a las nuevas necesidades, en especial de las que no pudieron ser previstas. Y siempre con un mínimo de exigencias.

Si esto no se prevé, lo más probable es que los hechos desborden a los textos y terminen arrasando todo lo existente. Por eso las cláusulas de revisión o reforma son siempre necesarias. Pues, por un lado, al fijar un procedimiento agravado para su cambio, se tiende a defender el texto frente a las mayorías veleidosas. Pero tampoco impide su cambio si es que se siguen los trámites existentes, que no pueden ser tan difíciles que a la larga lo impidan. De hecho, toda cláusula compli- 
cada y muy exigente puede terminar saltando por los aires. Así la prudencia política aconseja un procedimiento agravado, pero no imposible de seguir.

\section{REFORMA ¿TOTAL O PARCIAL?}

Un tema de gran debate es si una reforma constitucional puede ser total o parcial. En principio, y si nos atenemos a los estándares del constitucionalismo clásico, toda reforma sólo puede ser parcial, esto es, de alguno o algunos artículos y no de todos y menos afectando las líneas estructurales de la Carta. Si cambiamos todo, entonces más que reforma estaríamos, según señala C. Schmitt, ante una "destrucción» de la Constitución. Esto es válido hoy en día en la medida que la propia norma señala cómo hacer una reforma. Pero si la Carta acoge la tesis de que la reforma puede ser total o parcial, ésta última es la que prevalece y en este supuesto no sería deseable hablar de "destrucción" de la Constitución, sino más bien de "sustitución» de la Constitución, toda vez que si el constituyente originario previó la reforma total o la permitió, no se trata de destruir algo sino de cambiarlo acorde con lo que dice el texto, que en este punto ha dejado una permisividad total.

Pero aun dentro de este marco tan amplio previsto originalmente, es indudable que lo que no puede cambiarse es precisamente el «mecanismo procedimental» para la reforma, normalmente contenido en una disposición especial o final, que regula cómo hacer el cambio y que precisamente lo fundamenta. Esto es, aun en el extremo de una reforma total, ésta tiene que hacerse siguiendo los pasos indicados por la Constitución en su cláusula de reforma. De esta suerte, no se ha "destruido" nada, sino que ha operado una "sustitución" pacífica y ordenada, de acuerdo con lo previsto por ella misma.

\section{LOS LÍMITES DE LA REFORMA}

Aparte del respeto a la cláusula procedimental que luego puede ser cambiada en el nuevo texto, existe una gran discusión sobre los límites que tiene la reforma y que dista de ser pacífica. $Y$ es que existen una serie de límites que algunos se han encargado de señalar y de los que aquí haremos referencia, pero tan sólo de algunos de ellos.

Lo primero que cabe indicar es que en un mundo globalizado, ningún poder de reforma puede actuar al margen del escenario mundial y menos aún de la normativa internacional. Esto significa que una refor- 
ma total e incluso un poder constituyente originario tienen límites, aun cuando estos formalmente no existan. Así, la existencia de tratados o compromisos internacionales es un parámetro que no puede ser obviado, ya que en ellos lo que está afectado no es un Gobierno que siempre es transitorio, sino el Estado mismo. Igual podríamos decir en relación con los derechos humanos y los documentos supranacionales a los cuales nos hemos sometido.

Un segundo límite es lo que podemos llamar el «entorno social y cultural», es decir, aquellos elementos que actúan sobre el cuerpo político a fin de que tomen determinadas opciones políticas o que por el contrario, las rechacen. Así, grandes temas en materia económica, pueden ser sentidos como necesarios y el constituyente prefiere no tocarlos y dejarlos tal cual. Igual podríamos decir de opciones políticas, religiosas, etc. Son algo así como presiones invisibles sobre el cuerpo constituyente, que no se ven ni se pueden cuantificar, pero que existen. Evidentemente esto no es definitivo, pero en numerosas ocasiones observando determinas opciones normativas, ellas resultan explicadas por estos factores, que muchas veces resultan siendo condicionantes.

Desde otra perspectiva, tenemos lo que se conoce como «cláusulas pétreas" o de intangibilidad, que no pueden ser revisadas ni ser objeto de revisión en ninguna circunstancia. Es el caso de Alemania (Ley Fundamental de Bonn, art. 79), Italia (Constitución de 1947, art. 139), Francia (Constitución de 1958, art. 89) etc. Otros ordenamientos como el mexicano (Constitución de 1917) carece de límites, si bien esto ha causado una larga discusión doctrinaria.

En Perú hemos tenido un caso relativamente reciente en la Constitución de 1933, que señalaba en su artículo 142 lo siguiente:

«No hay reelección presidencial inmediata. Esta prohibición no puede ser reformada ni derogada. El autor o autores de la proposición reformatoria o derogatoria y los que la apoyen directa o inmediatamente, cesarán de hecho, en el desempeño de sus respectivos cargos y quedarán permanentemente inhabilitados, para el ejercicio de toda función pública».

Esta norma nunca más fue repetida, ni en la Carta de 1979 ni en la vigente de 1993.

Y por cierto que hay gran cantidad de Constituciones que no tienen límites para su modificación, con lo cual estamos ante un caso prima facie, de poder hacer una modificación total de la Constitucion, mediante una reforma. 
En este punto, sin embargo, ha surgido la tesis de los límites materiales implícitos, es decir, que aun cuando no existan expresas cláusulas de no revisión, este poder no puede ser total sino sólo parcial, pues existen normas, prescripciones o valores no escritos que así lo consideran. En el caso de la Argentina, en donde no existe cláusula expresa de irreformabilidad, algunos han sostenido la existencia de cláusulas intangibles implícitas (así, por ejemplo Bidart Campos). Otros sin embargo, han sostenido lo contrario (Ricardo Haro, Eduardo P. Jiménez, etc.)

El punto de vista antes señalado, es sin lugar a dudas, muy sugestivo, ya que tiene un fin conservador, es decir, que determinados aspectos básicos no se alteren mediante una reforma. El problema con este enfoque que tiene mucho de ideológico, es que como la irreformabilidad no existe expresamente sino que es construida a través de un proceso de razonamiento articulado, ésta no sólo no puede defenderse solidamente, sino que además pueden darse casos en los cuales surjan tesis diversas y hasta opuestas sobre lo que sería el límite material implícito, con lo cual quedaríamos a la larga entrampados en una discusión teórica sin posibilidad de ser resuelta y sin referente al que acudir. Es quizá la más sugestiva, pero la que mayores flancos ofrece al crítico desinteresado. Es decir, sostener la existencia de límites materiales implícitos puede a la larga ser un producto de la imaginación o de los buenos deseos del intérprete, que incluso pueden cambiar con el tiempo o tener consecuencias imprevistas.

Conviene además hacer una ulterior distinción: $Y$ es que no hay que confundir la existencia de un "entorno social y cultural» que ejerce presión o influencia sobre los legisladores que a su vez están en libertad de sentirla o no, y muy distinta es la tesis de que existen limites materiales implícitos, pues esto no sólo es más concreto, sino que presenta un carácter mandatario que la diferencia de la anterior y que no pasa de tener un carácter "ambiental» no imperativo.

\section{5. ¿QUIÉN HACE LA REFORMA?}

En este punto no hay mayor discusión, pero existen diversas modalidades para hacerla, gran parte de las cuales provienen también del modelo norteamericano. $Y$ ellas consisten básicamente en las siguientes:

a) la hace el propio órgano legislativo, a través de un procedimiento especial, 
b) una Convención especialmente convocada para ello (como lo fue la reforma argentina de 1994),

c) métodos heterodoxos pero democráticos (como es la previa consulta al electorado para llamar a una constituyente, como ha sucedido con la Constitución colombiana de 1991 y la venezolana de 1999).

Lo cual significa que las reformas, como fruto o expresión del poder constituido (frase que como se sabe remonta a Sieyés) debe hacerse siguiendo determinadas pautas, observando un procedimiento especial y desde un punto de vista jurídico-formal que por cierto puede adoptar muchas modalidades, de las que aquí me he limitado a señalar unas cuantas.

No obstante, cabe llamar la atención que muchas veces la reforma constitucional se hace a través de gobiernos de facto, como ha sucedido en el Brasil, en donde una larga dictadura militar no sólo aprobó una Constitución (la de 1967) sino que la modificó por sucesivos «actos institucionales». En el mismo sentido, en la Argentina la dictadura militar de 1972 modificó diversos artículos de la Constitución vigente en aquella época, y que surtieron plenos efectos. La consecuencia de estos actos que parten de gobiernos de facto es que pueden dar lugar a una nueva Constitución (el Brasil con la Carta de 1988 que los elimina) o simplemente quedar derogados con el advenimiento de un nuevo gobierno (Argentina). Hay casos que son incluso más patéticos: la Constitución argentina de 1949, aprobada durante el gobierno de Perón guardando las formalidades del caso (aun cuando hubo discusión sobre ciertos procedimientos), fue echada por la borda tan pronto el dictador fue derrocado en 1955, restableciéndose la antigua Carta de 1853, inferior formalmente a la nueva pero con mayor preferencia por parte de la clase política. Más tarde, llegado Perón al poder en 1973 mediante elecciones generales incontestables, no se atrevió a tocar la Carta de 1853 ni menos aun intentó restablecer la de 1949, demostrándose así que no obstante gozar del poder pleno en esa época, tuvo conciencia de las resistencias que originaría ese gesto suyo (Perón como se sabe, murió en el poder siendo sucedido por su esposa María Estela de Perón, que fue derrocada por un golpe de Estado poco después).

Estas son las realidades que nos muestra nuestra América, que no son ideales pero que enriquecen el panorama comparado. 


\section{EL CONTROL DE LA REFORMA}

Normalmente el control de la reforma se hacía a nivel sociológico o político, a través de movimientos políticos o por órganos de carácter político como pueden ser el Congreso o Parlamento. O peor aun, por golpes de Estado o movimientos revolucionarios. Sólo más tarde se empezó a pensar que debería existir un control jurídico, y esto si bien con antecedentes en el siglo XIX en los Estados Unidos, sólo se perfecciona en realidad en el siglo Xx. Es decir, el control de una reforma constitucional debe ser un control jurídico, ya que toda reforma se lleva a cabo por medio de una ley o norma equivalente. Lo que aquí tenemos sin embargo, son variantes, según los sistemas de control existentes.

La primera respuesta que surge sobre quién es el encargado de controlar una reforma, es la que determina que esta labor compete al Poder Judicial y en concreto a la Corte Suprema, como instancia final y definitiva del órgano judicial. Esto sucede dentro de los países influenciados por el modelo norteamericano de control judicial (judicial review) en donde se produce lo que se conoce técnicamente como desaplicación en el caso concreto de una norma considerada inconstitucional, con lo cual estamos ante acciones de carácter puntual. Sin embargo, esta decisión que no necesariamente es otorgada expresamente por la Constitución, sino que nace de la práctica judicial y más bien en tiempos recientes, queda reforzada por la fuerza del precedente, o sea, el stare decisis que obliga a las Cortes inferiores a seguir el razonamiento contenido en lo resuelto por el más alto Tribunal. Con lo cual se da cierta fijeza a las decisiones judiciales, que con el tiempo forman un cuerpo de doctrina sólida que puede durar y también sufrir algunas transformaciones, como se ha visto en varios de los países que siguen este sistema.

El otro modelo jurídico de control, es el de aquéllos que tienen un órgano concentrado para hacerlo, que puede estar dentro del Poder Judicial o fuera de él. Se está dentro del Poder Judicial con dos variantes: o dentro del conjunto de una rama judicial unida sobre todo con fines de organización (como son Colombia y Bolivia en América Latina y Alemania en Europa) o dentro de ella en forma expresa, pero funcionando con autonomía (es el caso sobresaliente de la Sala Constitucional de Costa Rica). O el órgano concentrado tiene autonomía plena, no sólo funcional sino operativa (como España e Italia en Europa, y Guatemala y el Perú en América Latina).

Sin embargo, también en los órganos concentrados y centralizados tenemos dos situaciones: la primera se da cuando dicho órgano tiene la 
facultad expresa de controlar las reformas constitucionales, aun cuando sea con matices (Colombia), y la segunda cuando dicho órgano no tiene facultades expresas para efectuar tal tipo de control, como es el caso del Perú. Sin embargo, dentro de este último supuesto se dan también dos situaciones: los que fiel a la dogmática se resisten o niegan a asumir tal control, con argumentos diversos (como por ejemplo la discutida tesis de las "cuestiones políticas»). $Y$ aquellos que yendo más allá y aprovechando el silencio normativo y enunciados genéricos, acometen tal tarea y emiten pronunciamientos en estos temas (como el Tribunal Constitucional peruano, como veremos más adelante).

\section{7. ¿CÓMO CONTROLAR A LOS CONTROLADORES?}

El Estado de Derecho postula desde sus inicios un equilibrio de poderes, una separación y un campo de actuación para cada uno de ellos. Al mismo tiempo, implementa todo un sistema de controles mutuos los cuales se entrecruzan entre sí, con la característica de que estos en algún momento tienen un punto de cierre; es decir, un punto de clausura en donde ya no se puede ir más lejos. Así sucede en todas partes, pues si todo estuviera indefinidamente sujeto a controles y controversias, la sociedad viviría en permanente litigio o sobresaltos sin seguridad para los ciudadanos. En el caso de los controles constitucionales o de controles de alto nivel, sucede que estos en algún momento se detienen y se llega a un punto en donde no hay retorno, por lo menos mientras se mantenga la formalidad democrática y el Estado de Derecho.

Lo anterior no impide que puedan surgir conflictos que no sean fáciles de solucionar o aun peor, que no puedan resolverse, y esto alcanza a las reformas constitucionales y también a las interpretaciones de la Constitución. Es la situación de la Corte Suprema de los Estados Unidos durante el periodo del new deal encabezado por el presidente F.D. Roosevelt, que se vio enfrentado a los jueces supremos que bloqueaban todas sus reformas. Es decir, magistrados muy conservadores que no veían con buenos ojos las medidas adoptadas por el Presidente en tiempos de crisis y que se resistían a aplicarlas. Esto motivó que el presidente Roosevelt iniciase todo un plan de ataque consistente en aumentar el número de magistrados supremos con personas más liberales, que contrarrestasen la arremetida de la Suprema Corte y además movilizando a la opinión pública. Al final, la medida no prosperó pues no recibió apoyo político, pero el impacto fue tan fuerte que por propia iniciativa la Corte Suprema empezó a desbloquear al Ejecutivo y desde 
entonces la situación cambió. Lo que demuestra que dentro de la democracia constitucional existen efectivamente armas para afrontar a estos poderes al parecer intocables, cuando se estima que se han excedido o están equivocados, lo cual en última instancia radica en la fuerza de la opinión publica, si es que existe y es madura y compacta en ciertos temas.

De ahí la importancia de estudiar, difundir y criticar los fallos judiciales, no sólo para mejor conocer la marcha institucional del país, sino porque de esa manera se contribuye a crear la comunidad de intérpretes constitucionales, como certeramente la ha llamado Peter Häberle. Y esto es precisamente lo que sucede en los Estados Unidos, en donde la opinión pública culta sigue muy de cerca los avatares de la Suprema Corte, estableciéndose así un diálogo de ida y vuelta entre los magistrados supremos y la comunidad política y jurídica, que a la larga resulta beneficioso para el país.

El ejemplo de lo que sucede en los Estados Unidos se ha ido extendiendo a algunos países europeos que cuentan con Tribunales Constitucionales, y también a los de la América Latina que teniendo Tribunal Constitucional o careciendo de él, viven en permanente contacto con las importantes decisiones de sus máximos órganos judiciales (Argentina, México y el Brasil).

Esta sería la respuesta a la interrogante planteada a principios de nuestra era por Juvenal, quien se preguntaba: ¿quién custodia a los custodios? (Sátira VI, 345-348).

\section{EL INICIO DE LA REFORMA CONSTITUCIONAL EN EL PERÚ}

El Perú vive en los actuales momentos un proceso algo dilatado de reforma constitucional, que no se sabe bien donde va a concluir, pero que ha mostrado diversos hechos relacionados con el tema central que nos ocupa.

Todo empezó cuando tras un largo régimen militar que duró doce años (1968-1980) entró en vigor una Constitución aprobada el año anterior, a la que se conoce por esa fecha: Constitución de 1979. Ha sido y es considerada modélica por los analistas y tuvo una gran influencia en el entorno latinoamericano, siendo ella misma, además, receptora de gran parte de los más novedosos aportes del constitucionalismo europeo de postguerra. Inició su andadura como queda dicho en 1980 y duró sin tropiezos durante dos regímenes: 1980-1985 y 1985-1990. En este último año sin embargo, un outsideringresó a la política (Fujimo- 
ri) y se encontró de pronto instalado en la primera magistratura, pero sin mayorías parlamentarias que lo apoyasen. Esto que no hubiera sido nada grave en cualquier país con mayor conciencia política, puso incómodo al Presidente Fujimori que desde un principio dio a conocer su ausencia de escrúpulos y su perfil autoritario, avalados en cierto modo, por una cultura poco democrática en el seno de la población. Fue así que pretextando obstáculos y falta de apoyo dio un golpe de Estado (1992) en el mejor estilo de Bordaberry, pero con mayor éxito que éste. Desde el poder y con el respaldo de las Fuerzas Armadas, disolvió el Congreso y desmanteló los demás órganos constitucionales, a los que quitó facultades o enervó en sus competencias, iniciando así un régimen autoritario franco y sin cortapisas, basándose tan solo en eventuales reclamos populares que lo apoyaban. Tal modelo plebiscitario no pudo mantenerse y por la presión internacional se vio obligado a convocar un órgano constituyente al que denominó «Congreso Constituyente Democrático" instalado en 1993 y que duró hasta el fin de su primer periodo (1990-1995). En el camino quedó discutida y aprobada la Constitución de 1993 vigente hasta el momento, que si bien tuvo algunos avances importantes —como fue remozar la parte económica y otros ajustes que eran necesarios en el Poder Judicial, Defensoría del Pueblo, etc.- en otros representó un notable retroceso - derechos humanos, descentralización, estructura del órgano electoral y del Congreso, etc.- dándose así una nueva Constitución calcada de la anterior, pero en conjunto inferior a ésta.

Sin embargo, la nueva Carta fue aprobada plebiscitariamente en votación discutida y rige desde entonces. Lo más novedoso y ajeno a la tradición histórica del país fue la reelección presidencial inmediata -que desde entonces varios más han imitado en nuestra Américaque lo hizo reelegirse en 1995 y nuevamente en 2000. Sin embargo, por un raro proceso de implosión —el descubrimiento de una larga red de corrupción y el manejo arbitrario del Estado en los meses de agosto y setiembre de ese año- llevó al mandatario a un largo periplo por el Oriente Ilegando finalmente a la ciudad de Tokio, cuna de sus ancestros, desde donde renunció al cargo vía fax (la renuncia fue dejada de lado y el Congreso lo destituyó con una posterior inhabilitación). Acto seguido, se reformó la Constitución y se convocaron elecciones generales para el año 2001. Fue elegido Presidente para ese corto periodo de transición Valentín Paniagua, en su calidad de Presidente del Congreso.

Entre otras preocupaciones que tuvo el gobierno de Paniagua, fue importante el problema constitucional. Esto es, cómo mantener una Constitución fruto de un innecesario golpe de Estado, que en sí misma 
era defectuosa y que además había sido utilizada para cometer toda clase de estropicios.

Así la cosas, el presidente Paniagua creó una comisión de 28 expertos en el mes de mayo de 2001, la cual entregó su informe final el 16 de julio del mismo año, que ponía en claro que no podía mantenerse la Constitución de 1993 y que había que retomar la Constitución de 1979, con diversos ajustes y afinamientos y para lo cual señalaba determinadas alternativas o medios para llevarlo a cabo.

\section{LA APATÍA CONSTITUCIONAL DEL RÉGIMEN DE TOLEDO}

Llegado al poder en julio de 2001, el nuevo régimen de Toledo se envolvió en un mar de palabras y de abundantes promesas jamás cumplidas, pero no tocó el problema constitucional. En realidad no le interesaba o quizá no lo entendía, pero su entorno veía con buenos ojos la "parte buena» de Fujimori, entre las que estaba según parecía, la Constitución de 1993. A esto se añade que había la sospecha de que el propio Toledo se había beneficiado con el apoyo del fujimorismo y que él mismo andaba rodeado por varios de ellos o que habían dejado de serlo o que habían ayudado a constitucionalizar a Fujimori en 1993. Lo concreto es que no hubo ni una sola palabra a favor del cambio o de la reforma constitucional, sobre lo cual se guardó el más severo silencio.

No obstante, sin querer, percibieron que los prometidos gobiernos regionales durante la campaña electoral no existían y se dieron cuenta que la Carta de 1993 no sólo tenía carencias, sino que no gozaba de mucho predicamento en la opinión pública.

Por eso y a fin de calmar críticas de otros frentes, precipitadamente aprobaron en diciembre de 2001 la ley 27600 la cual, entre otros puntos, disponía que la Comisión de Constitución del Congreso elaborase y aprobase un nuevo texto de Constitución del Estado que remplazase a la anterior, haciendo la salvedad de que este proyecto debía respetar la Constitución histórica y en especial la Constitución de 1979. Y sobre esa base se trabajó durante algunos meses, fruto de lo cual fue un anteproyecto inmenso, repetitivo, lleno de imprecisiones, indecorosamente armado, que fue en gran parte aprobado en el Pleno y nunca terminado. Es decir, por diversas razones y sobre todo por la deficiencia en el trabajo, el Congreso al final paralizó la pregonada reforma constitucional (junio de 2003). Luego Toledo ha hecho algunos gestos a favor de la reforma, planteándola a través del Ilamado "Acuerdo Nacional» o de 
una facultad constituyente para el próximo Congreso que se instale el 2006, pero todo no ha pasado de buenas intenciones, al faltar acuerdo político entre las diversas tiendas partidarias del Congreso, incluyendo la que apoya a Toledo. En la forma se han hecho algunos cambios pequeños, pero otros que fueron planteados — como el retorno a la bicameralidad - no lograron su objetivo. En buena cuenta, se sigue contando con una Constitución aprobada hace doce años por Fujimori y al parecer se vive feliz con ella. Adicionalmente, ciertos grupos empresariales la defienden cerradamente, por considerar que ella garantiza muy bien las inversiones, lo cual decididamente es una falacia - jamás las inversiones han sido protegidas por una Constitución, sino sólo por un conjunto de situaciones que hacen atractivo un país al inversionista extranjero-.

Esta situación de indefinición, por un lado, y de respeto a un texto como el de 1993, por otro, es lo que ha originado algunos de los problemas que analizamos más adelante.

\section{LA UBICACIÓN DEL TRIBUNAL CONSTITUCIONAL, SUS ANTECEDENTES Y SITUACIÓN ACTUAL}

El Perú tuvo durante largos años el llamado sistema difuso de control constitucional, encomendado al Poder Judicial, si bien esto sólo resultó operativo a partir de 1963. Pero en 1979, con la Constitución de ese año, al lado del control difuso se introdujo un órgano concentrado de control a través del denominado entonces Tribunal de Garantías Constitucionales - nombre tomado de la Segunda República Española de 1931-y que funcionó sin interrupciones desde 1982 hasta 1992, en que fue desactivado como consecuencia del golpe de Estado de ese año.

Al discutirse la Constitución de 1993 no se contempló en sus primeros tramos esta modalidad, que sólo se incorporó al final del debate constituyente muy a desgano y como concesión a la oposición y a una opinión pública recelosa. Lo cierto es que en la nueva Carta se le cambió de nombre - lo que se venía demandando en los medios académicos-y se le llamó Tribunal Constitucional, al cual se le adicionaron algunas competencias. Es decir, no sólo revisión de determinados procesos constitucionales (Ilamados garantías constitucionales) sino una acción o proceso de inconstitucionalidad muy amplio contra toda ley o norma con rango de ley que afectase directa o indirectamente a la Constitución. $Y$ adicionalmente otro proceso para dirimir conflictos de competencia. 
Al igual que la Carta de 1979, la de 1993 mantiene el Tribunal Constitucional al margen de los poderes del Estado, como ente autónomo encargado del control de la constitucionalidad y de la defensa de los derechos fundamentales. Y sin vínculo alguno con el Poder Judicial.

Factor nuevo ha sido la elección de los magistrados del Tribunal Constitucional, que ahora proviene del Congreso de la República por una mayoría calificada de dos tercios del número legal de sus miembros (80 votos sobre 120 que es el número de congresistas). Esto ha hecho más difícil la elección de los magistrados, pero al mismo tiempo les da más independencia, si bien es cierto que no fue así al principio. Por otro lado, el magistrado dura en su cargo cinco años y no hay posibilidad de reelección inmediata.

Cabe acotar no obstante, que sus competencias están tasadas y lo que puede hacer en comparación con otros Tribunales Constitucionales es poco, ya que tales competencias son numerus clausus. $Y$ entre ellas, aparte de la defensa de la Constitución y de los derechos humanos, no se encuentra nada que le de competencia para poder pronunciarse sobre reformas constitucionales que al ser aprobadas por una ley, pasan a integrar y ser parte de la misma Constitución. De hecho, ninguna de las anteriores Constituciones dio esta facultad a ningún órgano, y el único que ejerció ese control en el pasado fue el mismo Congreso (mediante ley 10334 de 1945 declaró inconstitucionales y sin efecto alguno las reformas constitucionales hechas por el plebiscito de 1939).

No obstante que en la Constitución de 1993 no existe un solo dispositivo que otorgue competencias expresas al Tribunal Constitucional en materia de control de reformas constitucionales, éste lo ha hecho ante la presión de diversos grupos que instauraron procesos con tales fines en dicha sede. Veamos ahora cuáles han sido.

\section{LAS SENTENCIAS DEL TRIBUNAL CONSTITUCIONAL}

El Tribunal Constitucional tiene un total de 7 miembros y actúa generalmente en Pleno. Tratándose de procesos en defensa de los derechos fundamentales, se divide en salas de 3 miembros, de conformidad con lo que señala su Reglamento Normativo vigente (2004).

Sus competencias en sentido amplio son dos: la primera destinada a resolver procesos sobre desconocimiento o violación de derechos fundamentales; la segunda sobre el reconocimiento de la normativa constitucional o su supremacía. Tiene su propia ley orgánica que regula su funcionamiento. Recientemente el 1 de diciembre de 2004 ha en- 
trado en vigor el Código Procesal Constitucional que precisamente desarrolla los procesos que ante él se sustancian — si bien algunos, sobre todo los de defensa de los derechos fundamentales, llegan a su conocimiento sólo en ultima instancia y si han sido denegados previamente por el Poder Judicial-. Se trata pues, de competencias en parte compartidas con el Poder Judicial — si bien en un porcentaje minoritarioy adicionalmente de competencias exclusivas.

Su técnica, en lo que a redacción de sentencias se refiere, no ha sido muy depurada. Son por lo general textos largos y tediosos, repletos de citas, con argumentaciones innecesarias y con un extremo afán didáctico que a veces confunde más que aclara. Algunas sentencias parecen artículos de alta divulgación para medios especializados, con la salvedad de que no alcanzan el nivel académico como para que así se les considere. Su estructura es pesada y la presentación estilística es barroca, probablemente fruto de las varias manos que han intervenido en su redacción. No obstante estas deficiencias que las hacen poco atractivas, han existido importantes pronunciamientos tomados con decisión y valentía y en muchos sentidos con carácter innovador.

Los casos más significativos en el punto que nos interesa, son los siguientes:

a) Sentencia de 21 de enero de 2002 (exp. 014-2004-Al/TC) recaída en el proceso de inconstitucionalidad contra la ley 27600 , que estipulaba una reforma total de la Constitución desde el Congreso de la República. Planteada por el Colegio de Abogados del Cusco, sostenía que lo que pretendía la referida ley 27600 era aprobar una Constitución nueva en el seno del Congreso y que como quiera que esto sólo podía hacerlo el pueblo representado en un Congreso u órgano constituyente, había existido un exceso o usurpación de funciones. En su pronunciamiento, el Tribunal Constitucional en medio de diversas concesiones a la demanda, señaló sin embargo que la ley en cuestión autorizaba a preparar un proyecto a una Comisión parlamentaria; que la Comisión tenía que dar cuenta al Pleno para que aprobase la nueva Constitución y que para eso debería tomar en consideración lo que denominaba "constitución histórica" y en especial la Constitución de 1979, pero que era factible hacerlo, esto es, se podía hacer una reforma desde el Pleno, aun cuando fuese de carácter total, con la condición de que luego fuera sometida a referéndum. Agregaba el Tribunal que si bien el texto podía ser nuevo en cuanto a su forma o manera de presentarse, tenía que respetar ciertos contenidos históricos y teóricos básicos. Es decir, existe un "núcleo duro" que no puede ser cambiado como son la libertad, la dignidad, la soberanía del pueblo, entre otros, que son los 
valores que la sentencia rescata y da como válidos y que constituirían, según parece, algo así como límites materiales implícitos que el propio Tribunal ha descubierto y señalado como tales. En medio de estas afirmaciones la sentencia se extendió en dar pautas, orientaciones y consejos sobre cómo hacer una nueva Constitución y se pronunció sobre temas y tópicos que en rigor eran innecesarios. Confusa en su redacción y presentación, fue sin embargo definida en lo básico que se le solicitaba.

b) Sentencia de $1 .^{\circ}$ de diciembre de 2003 (exp. 0006-2003-Al/TC) que está vinculada con las atribuciones del Congreso y sobre el denominado en nuestra tradición "juicio político». En este caso muy sonado por sus implicaciones políticas, el Tribunal Constitucional dio un paso muy audaz, pues sostuvo que ciertas normas de la Constitución eran inconstitucionales y exhortaba al Congreso a modificarlas. Se trataba por cierto de un exceso, pues el Tribunal Constitucional es el controlador de la constitucionalidad y no de la Constitución, a la que debe interpretar en consonancia consigo misma como señala Hesse, y no en señalar inconstitucionalidades más aparentes que reales. Esta sentencia muy lamentable, no ha tenido felizmente mayores consecuencias.

c) Sentencia de 1 de diciembre de 2003 (Exp. 014-2003-Al/TC) presentada por más de cinco mil ciudadanos convocados por Alberto Borea Odría, un constitucionalista y político distinguido que buscaba que el Tribunal Constitucional declarase inconstitucional la Constitución de 1993, a la cual negaba el carácter de Constitución y calificaba de «documento" dado por la dictadura para oscurecer el Estado de Derecho en el país.

El Tribunal Constitucional coincidiendo con la demanda en que la Carta de 1993 era espuria, aceptó sin embargo que el tiempo la había legitimado y que debería ser observada mientras no fuese reemplazada por otra, procediendo a hacer una exhortación al Congreso para que así lo hiciese (exhortación que no le correspondía hacer). Agregó que el Tribunal Constitucional había sido elegido precisamente bajo el procedimiento señalado en ese "documento" de 1993, que era por así decirlo su partida de nacimiento y los mismos hechos la habían legitimado en el tiempo, agregando además que el Tribunal Constitucional no era competente para declarar inconstitucional un "documento" que en el fondo era una Constitución.

d) La Sentencia de 3 de junio de 2005 (exp. 050-2004-Al/TC al que se acumulan otras demandas similares) es muy reciente y vale la pena detenerse en ella. Es excesivamente larga, llena de razonamientos de diverso orden, en parte innecesarios y de fatigosa lectura. Se trata de un 
proceso iniciado contra la Ley 28389 que modificó parcialmente la Constitución realizando diversos ajustes al régimen pensionario establecido por el Estado. Es en realidad la primera vez que se presenta una demanda de esta naturaleza, en la cual se quiere cuestionar directamente la constitucionalidad de una reforma constitucional, precisamente a través del Tribunal Constitucional. En esta oportunidad la sentencia acudió a la tesis del "contenido esencial» de los derechos, acuñada por la doctrina alemana y con antecedentes en el constitucionalismo norteamericano, para establecer que la reforma al régimen pensionario lo que había hecho era adecuar el régimen a las necesidades del Estado sin eliminarlo, y más bien estableciendo condiciones para su supervivencia. De tal suerte, la reforma constitucional no había modificado ni violentado los derechos fundamentales (dignidad del hombre, derecho a la pensión, etc.) por lo que devenía improcedente la demanda.

Esta causa terminó así de afianzar una competencia que el Tribunal Constitucional se había arrogado: supervisar, sin tener competencia para ello, la constitucionalidad de una reforma constitucional, basándose en la existencia de una serie de límites materiales implícitos, que han sido creados pretorianamente y apunta de razonamientos y opciones políticas.

\section{A MODO DE CONCLUSIÓN}

El problema de la constitucionalidad de una reforma constitucional que tanta literatura ha ocasionado, no está aún resuelto. Tampoco lo está la manera como se dan nuevas Constituciones, pues nuestra América muestra una gama infinita y muy variada de ellas. Lo que existe cada vez con mayor fuerza, es la necesidad de que las reformas constitucionales tengan algún tipo de control que no sea el meramente político. Por tanto, poco a poco los órganos encargados de la constitucionalidad (Cortes Supremas, Salas Especiales, Tribunales o Cortes constitucionales) han ido asumiendo estas funciones a contrapelo de las normas y muchas veces en oposición a ellas, sin que nada exista para poder impedirlo, por lo menos legalmente y sin que los actores políticos lo hayan objetado.

Dentro de esta actividad, problema importante es el relacionado con los límites de toda reforma constitucional. Lo ideal es que éstos no existan o existan en grado muy pequeño, y de preferencia de manera expresa o sea con cláusulas realmente existentes. Pero todo se complica cuando al no existir límites materiales expresos, se postula la 
existencia de límites materiales implícitos, que no son otra cosa que una creación ideológica cercana al Derecho Natural, imposible de controlar y que además puede cambiar en el tiempo. En realidad, si el constituyente no puso límites materiales expresos es fácil llegar a la conclusión de que no tuvo interés en ellos y menos aún pretendía establecerlos, pues si hubiera sido ese su deseo, lo hubiera hecho. Pero al no hacerlo, es más que discutible que alguien que no es el constituyente pueda crearlos, sea la Corte Suprema o un Tribunal Constitucional. $Y$ en esos casos, los resultados obtenidos son generalmente muy vagos, fruto de intereses, especulaciones o ideas políticas demasiado coyunturales que pueden cambiar de tiempo en tiempo, más aun en países como los nuestros que no tienen la rigidez del precedente, propio de los países con tradición jurídica anglosajona. Y menos una sólida cultura cívica y una definida tradición constitucional.

Pero esta realidad existe y así hay que señalarlo, con sus peligros y eventuales ventajas.

\section{BIBLIOGRAFÍA}

El tema de la reforma ha sido objeto de numerosa y cada vez más creciente bibliografía. De hecho, prácticamente todos los textos en materia constitucional (tratados y manuales) la consideran en su exposición y sin contar con la bibliografía local que se produce o ha producido con motivo de alguna importante reforma (por ejemplo, la argentina de 1994 o la actualmente en proceso en México, abundantísima y variada) las que no se citan para no alargar esta lista que pretende ser sumaria. Entre la bibliografía reciente mencionamos de manera especial: Benito Alaez CoRRAles, Los límites materiales a la reforma de la Constitución española de 1978, BOE-CEPC, Madrid 2009; Miguel Carbonell, Constitución, reforma constitucional y fuentes del Derecho en México, UNAM, México 2000; PEDRO DE VEGA, La reforma constitucional y la problemática del poder constituyente, Edit.Tecnos, Madrid 1985; Javier Pérez Royo, La reforma de la Constitución, Pub. del Congreso de los Diputados, Madrid 1987; CARLos DE CABO MARTín, La reforma constitucional en la perspectiva de las fuentes del derecho, Edit. Trotta, Madrid 2003; IVÁN EsCOBAR FORNOS, La reforma constitucional, Hispamer, Managua 2004; JosÉ VICENTE HARO, Sobre los límites materiales de la enmienda y la reforma constitucional en "Revista de Derecho Constitucional» (Caracas) núm. 8, julio-diciembre 2003 y Gonzalo RAmíREZ CLEVES, Los límites a la reforma constitucional y las garantías límites del poder constituyente, Universidad Externado de Colombia, Bogotá 2003. 
La reciente obra de SERgio M. DíAz RıcCl, Teoría de la reforma constitucional, UNAM-Complutense de Madrid-Ediar, Buenos Aires 2004, debe considerarse la más amplia y comprensiva existente sobre la materia y no sólo en idioma español (descartando por cierto las publicaciones en varios tomos que existen de carácter documental, sobre todo en los Estados Unidos de América).

Entre los clásicos son de utilidad JAMES BRYCE, Flexible and rigid constitucions en "Essays in History and Jurisprudence", Oxford at the Clarendom Press, 1901, tomo I, pp. 145-252 (hay edición en castellano); GeORge JeLLINEK, Reforma y mutación de la Constitución, CEC, Madrid 1991 y en nuestra área el de ADOLFO G. POSADA, La reforma constitucional, Lib. Gen. de V. Suárez, Madrid 1931. Otros autores que han tocado el tema de la reforma dentro de un conjunto mayor de su obra pero que han ejercido gran influjo son HANS KELSEN, Teoría general del Estado, Edit. Labor, Barcelona 1934 (el original es de 1925); CARL SCHMITT, Teoría de la Constitución, Alianza Editorial, Madrid 1990 (el original es de 1928) y Karl LöEWEnStein, Teoría de la Constitución, Edit. Ariel, Madrid 1970 (el original se publicó en inglés con otro título, en 1957).

Entre nosotros el tema ha sido abordado pioneramente por SIGIFREDo ORBEgoso V. El poder constituyente y otros ensayos, Edit. Normas Legales, Trujillo 2002 y luego con intensidad a partir del proceso de reforma iniciado en 2001 y sobre el que volvemos más adelante.

El problema de la reforma tiene como supuesto el hecho de que los textos deben durar, pero en rigor tampoco pueden ser eternos. Esto lo vio muy bien Pound en la cita antes señalada y que es la siguiente: "Law must be stable and yet it cannot stand still" (el derecho debe tener estabilidad y sin embargo no puede permanecer inalterable) en Interpretations of legal history, The Mac Millan Co, New York 1923, p. 1; con reimpresiones, hay traducción castellana. El mismo Kelsen señaló al respecto: «... es jurídicamente imposible la reforma de una constitución o precepto constitucional declarado irreformable.... (pero esto) puede ser enormemente inoportuno, puesto que de hecho no podrá imponerse una constitución que no está de acuerdo con las necesidades de la época..." (cit. p. 332). Un panorama de este tópico cf. Le dinamiche della Costituzione por G. MorBIDELLI en el colectivo «Diritto Costituzionale italiano e comparato" por G. Morbidelli, L. Pegoraro, A. Reposo y M. VolPI, Monduzze editore, Bologna 1997; JoRgE R. VANOSSI, Teoría constitucional, Ed. Depalma, Buenos Aires 1975, tomo I; SEgundo V. Linares QuintanA, Tratado de la Ciencia del Derecho Constitucional, Edit. Plus Ultra, 2da ed, Buenos Aires 1978, tomo III, pp. 225-299; NÉSTOR P. SAgüÉS, Teoría de la Constitución, Edit. Astrea, Buenos Aires 2001, pp. 
295-344; EdUARDO Rozo ACUÑa (a cura di) I procedimenti di revisione costituzionale nel diritto comparato, Universitá degli studi di Urbino, Napoli 1991; AlLAN R.BREWER-CARías, Modelos de revisión constitucional (reformas y enmiendas) en América Latina en "Constitución, democracia y control del poder», Univ. de los Andes-Editorial Jurídica VenezolanaCIEPROL, Mérida (Venezuela) 2004 y Jorge MiRANDA, Teoría do Estado e da Constituiçâo, Editora Forense, Río de Janeiro 2003, pp. 389-430 (existe una edición previa hecha en Portugal).

A nivel de la dogmática, la que primero abordó el problema de la reforma constitucional fue la Constitución de los Estados Unidos de 1787 (art. V) que prevé dos formas de hacer la reforma: a) a través de la aprobación de los 2/3 del Congreso y la subsiguiente aprobación de las legislaturas de los Estados o, b) a través de una Convención convocada al efecto por $2 / 3$ de los estados y ratificada en sus reformas por las convenciones de los estados. Lo único que ha sido operativo ha sido el primer sistema, que ha llevado a cabo únicamente 27 reformas en más de 200 años; el segundo sistema (imitado por muchos países como la Argentina) jamás ha sido empleado. En Estados Unidos se utiliza preferentemente la palabra "enmienda" en sentido genérico, que prácticamente es total con una sola excepción que no puede ser superada y que tiene un trasfondo histórico (como la privación de la igualdad en el Senado a los Estados federados). Por tanto, el sentido de la «amending power" alcanza a todo tipo de reformas, tanto a nivel federal como, en general, de los Estados. De lo que se desprende fácilmente que el tema de la reforma constitucional no tiene mayor importancia en los estudios constitucionales de los Estados Unidos, aun cuando hay literatura al respecto. En el fondo, más que acudir a la reforma que es complicada, los grandes cambios se han hecho mediante interpretación jurisprudencial Ilevada a cabo por la Corte Suprema, aprovechando la existencia de un texto relativamente breve y de gran cantidad de enunciados genéricos, sin contar con la existencia de constituciones en todos los Estados, que si bien observan el marco federal, se mueven con libertad dentro de sus límites territoriales. La poca importancia del tema de la reforma lo confirmamos al revisar dos importantes manuales de las últimas décadas que apenas dedican espacio a la reforma; cf. EDWARD S. CoRWIN, The Constitution and what it means today, revised by $\mathrm{H}$. W. Chase and C.R. Ducat, Princeton University Press, N.J. 1978 (la reforma a pp. 268-271) y John E. NowaK y Ronald D. Rotunda, Constitutional Law, West a Thomson business, St. Paul, Minn. 2004 (pp. 130-132). Una polémica clásica, que llamó la atención a C. Schmitt es la sostenida en la Harvard Law Review por WILLIAM M.MARBURY y W. L. FRIERSON en 1919; recientemente en la misma revista entre Walter Dillinger y 
Lawrence Tribe (1983). El libro de Lester B. Orfield, Amending the federal constitution The University of Michigan Press, Chicago 1942, sigue siendo de obligada consulta (hay reimpresiones).

En México se utiliza la palabra "reforma" que se entiende que puede ser total,y aún cuando se discute este enfoque nadie olvida que en la práctica ha habido tantas reformas a la Constitución de 1917 (no se sabe su número con exactitud, pero se calcula que son más de 600) que algunos dudan que quede algo del texto original, salvo algunos fines o directivas políticas debidamente actualizadas; cf. HÉCTOR FIX-ZAMUDIO y Salvador Valencia Carmona, Derecho Constitucional Mexicano y comparado, Edit. Porrúa-UNAM, México 2005 y la voz reforma constitucional a cargo de JORGE CARPIZO y Miguel CARBONELL en "Enciclopedia Jurídica Mexicana», Edit. Porrúa-UNAM, México 2002, tomo VI; vid. además JAIME CÁRDENAS GRACIA, El procedimiento para la revisión integral de la Constitución de 1917 en "Cuestiones Constitucionales" enero - junio de 2005, N. ${ }^{\circ} 12$.

En Italia se habla del poder de "revisione», cf. GIUSEPPE DE VERGOTTINI, Diritto Costituzionale, CEDAM, Padova 2000; LIVIO PALAdIN, Diritto Costituzionale, CEDAM, Padova 1998; Augusto BARBERA y CARLo Fusaro, Corso di diritto pubblico, II Mulino, Bologna 2002 (a pp. 401 una referencia a las últimas reformas).En Francia se utiliza la voz "revisión" y es frecuente en la doctrina la diferencia clásica entre «pouvoir constituant originaire" y "pouvoir constituant dérivé» o "constitué» (cf. LouIS FAvoreu et alter, Droit constitutionnel, Dalloz, 4ta. édicion, Paris 2001, pag. 96 ss. y Francis Hamon y Michel Tropper, Droit Constitutionnel, L. G. D. J., Paris 2003, pp. 42-44; 483-498). En Alemania se habla de "revisión" cf. KLAUS StERN, Derecho del Estado de la República Federal Alemana, CEC, Madrid 1987 y el clásico ensayo de OTTo BACHOF, Normas constitucionais inconstitucionais? Coimbra 1994. En España se hace referencia a la reforma (que puede ser total o parcial) cf. Javier Jiménez Campo, Algunos problemas de interpretación en torno al Título $X$ de la Constitución en "Revista de Derecho Político», núm. 7, 1980; Francisco FERnÁNDEZ SegAdo, El sistema constitucional español, Edit.Dykinson, Madrid 1992; EnRIQue Álvarez Conde, Curso de Derecho Constitucional, Edit. Tecnos, Madrid 1999, 2 vols.; Francisco Balaguer CALLEJón et alter Derecho Constitucional, Edit. Tecnos, Madrid 1999, 2 vols.; ANTONIO ToRRES DEL Moral, Principios de Derecho Constitucional español, Univ. Complutense de Madrid, Madrid 2004, 2 tomos y JAVIER PÉREZ RoYo, Curso de Derecho Constitucional, Pons ediciones, Madrid 2004. Un gran panorama puede verse en la voz reforma constitucional en Manuel Aragón (coordinador) Temas básicos de Derecho Constitucional (varios autores) Edic.Civitas, Madrid 2001, tomo I. 
Casos especiales lo constituyen Brasil y Venezuela. Así, José Afonso da Silva señala que los constitucionalistas brasileños han usado indistintamente y con vacilaciones los términos reforma, enmienda, revisión y modificación constitucional, pero que hay cierta tendencia a preferir el vocablo "reforma" como algo genérico que abarca todas las modalidades, señalando que la Constitución vigente de 1988 utiliza la palabra "enmienda" en su artículo 60 (cf. sus dos obras Curso de Direito Constitucional Positivo, Malheiros Editores, Sâo Paulo 2005 y Comentario contextual á Constituiçâo, Malheiros Editores, Sâo Paulo 2005; vid. además Luiz Pinto FerReIRA Curso de Direito Constitucional, Edit. Saraiva, Sâo Paulo 1999; Paulo Bonavides Curso de Direito Constitucional, Malheiros Editores, Sâo Paulo 2003 (cap. VI) y André Ramos TAVARES Curso de Direito Constitucional, Edit. Saraiva, Sâo Paulo 2003.

En Venezuela se ha introducido desde la Constitución de 1961 y mantenida en la vigente de 1999, la distinción entre "enmiendas" y "reformas", diferenciadas ambas por el procedimiento y por el alcance: así, mientras la primera opera sobre aspectos poco importantes, la segunda tiene un alcance mayor; en ambos casos, se somete lo resuelto a referendo: cf. Allan R. Brewer-Carías La Constitución de 1999 (Derecho constitucional venezolano), Edit. Jurídica Venezolana, Caracas 2004, tomo I; Freddy Zambrano, Constitución de la República Bolivariana (comentada), Edit. Atenea, Caracas 2004, tomo II, pp. 566-584 e HILDEGARD Rondón de SAnsó, Análisis de la Constitución Venezolana de 1999 Edit. Ex Libris, Caracas 2002, pp.367-375. Los problemas de una reforma complicada llena de vicisitudes políticas es lo que ocurre actualmente en Bolivia; vid. José ANTONIo RIVERA SANTIBÁÑEZ El proceso constituyente en Bolivia, Grupo Editorial Kipus, Cochabamba 2005.

Interesante es el caso señalado por Vergottini en relación con el Portugal: la ley de revisión de 30 de setiembre de 1982 afectó partes sustanciales de la Constitución de 1976 todavía vigente, a tal extremo que el modelo socialista fue cambiado por un modelo liberal, eliminó la preponderancia militar, creó el Tribunal Constitucional y otra posterior la amplió en 1989, con lo cual se dio el caso de una reforma que afectó las bases mismas de la Constitución pero manteniendo formalmente la misma, sin haber sido cuestionada desde entonces (cf. Diritto Costituzionale Comparato, CEDAM, Padova 2004, vol. I, pp. 161-174 en donde ofrece un panorama sobre la cuestión de carácter más bien descriptivo)

La Argentina es un caso especial, pues siguiendo el modelo norteamericano requiere a) aprobar por ley expresa la necesidad de la reforma y b) convocar a una convención especial que llevará a cabo esa reforma; vid. GERMÁn J.BIDART CAMPOS, Manual de la Constitución refor- 
mada, EDIAR, Buenos Aires 1996, tomo I; RICARDo HARO, Curso de Derecho Constitucional Argentino, Ed. Advocatus, Córdoba 2003, tomo I, pp. 88-103; EduARdo P. JimÉneZ, Derecho Constitucional Argentino, Ediar, Buenos Aires 2000, tomo I, pp. 245-279; ambos autores discrepan de Bidart Campos al no admitir límites materiales implícitos. El reciente caso "Fait" ha posibilitado el control judicial de la reforma constitucional, si bien esto ha sido muy debatido; cf. ANTONIO MARía HERNÁNDEZ (h), El caso "Fait" y sus implicancias constitucionales,Academia Nacional de Derecho y Ciencias Sociales de Córdoba, Córdoba 2001 y GREGORIO BADENI, Tratado de Derecho Constitucional, Ed. La Ley, Buenos Aires 2004, tomo I, pp. 175-179.

En Colombia se dejó de lado la vieja Constitución de 1886 por un procedimiento no previsto en ella, que dio nacimiento a la vigente Constitución de 1991. Ésta permite con modalidades su reforma parcial o total, sea a través del Congreso, de una asamblea constituyente o referendo (consulta popular) y que al final se reflejan en los denominados "actos legislativos" el último de los cuales que permite la reelección presidencial inmediata (2004) ha sido cuestionada ante la Corte Constitucional, que en principio sólo puede declararla «inexequible» por vicios de procedimiento; cf. JACOBO PÉREZ EsCOBAR, Derecho Constitucional Colombiano Edit. Temis, 6ta edición, Bogotá 2003; DIEGO YounES Moreno, Derecho Constitucional Colombiano Edit. Ibáñez, 6ta. edición, Bogotá 2005 (reseña las reformas de la Carta de 1991 a pp. 453-534) y JaIME VIDAL PERdomo, Derecho Constitucional General e instituciones políticas colombianas, Legis, 9na. edición, Bogotá 2005.

En Uruguay la Constitución de 1967 admite la reforma parcial o total, bajo cuatro modalidades: a) iniciativa popular, b) iniciativa legislativa, c) convención nacional constituyente y d) leyes constitucionales; cf. Martín Risso FerRand, Derecho Constitucional, Fund. de Cultura Universitaria, Montevideo 2005, tomo I (el capítulo V está dedicado a la reforma de la Constitución)

Sobre la situación del Perú puede verse, sin ánimo exhaustivo, las publicaciones especializadas dedicadas al problema de la reforma como son: Actualidad Jurídica, tomo 100, marzo de 2002 (publicación de "Gaceta Jurídica»); AA.VV. Reforma constitucional, Fund. Ebert y Fund. Luis de Taboada Bustamante, Arequipa 2001; AA.VV. Propuestas de reforma constitucional, Univ. Católica Santa María, Arequipa 2002; Aequm et Bonum, núm.1, enero-junio de 2003; Revista Peruana de Derecho Público, núm. 3, julio-diciembre de 2001; Revista Institucional (editada por la Academia de la Magistratura) núm. 6, junio 2002. En cuanto a libros, cf. Alberto Villacorta MichelenA, Los límites de la re- 
forma constitucional, Edit. Grijley, Lima 2003 (prácticamente el único publicado entre nosotros sobre el tema) y NÉSTOR P. SAGÜÉs y JosÉ F. PALOMINO MANCHEGO, Imprevisión y reforma: dos problemas contemporáneos del Derecho Constitucional, Cuadernos de la Asociación Peruana de Derecho Constitucional, Lima 2005. Entre los numerosos artículos publicados y sin contar los incluidos en las revistas o libros colectivos que dedicaron expresamente un volumen al tema, tenemos: ELOY ESPINOSA-SALDAÑA BARRERA, Algunas cuestiones sobre reforma constitucional así como acerca de los presupuestos sociales y políticos para su puesta en práctica en nuestro país en "Revista Jurídica del Perú», núm. 22, 2001; CÉsar LANDA ARroyo, La reforma constitucional en el Perú como un estadio del Estado Constitucional en "Derecho y Sociedad", núm. 20, 2003; Raúl Chanamé ORBe, La reforma constitucional en el Perú en AA.VV. "El derecho peruano frente a los cambios sociales, avances tecnológicos y una nueva Constitución", J. A. RIVERA Oré y RicARDo VeLÁSOUEZ RAMíREZ, coordinadores, CEDDAL, Universidad Inca Garcilaso de la Vega, Lima 2003; DAVID DUMET DELFín, El proceso de reforma de la Constitución de 1993 y sus límites, en "Revista de Derecho» (Univ. de Piura), núm. 3,vol. 2; Enrique Bernales Ballesteros, Los caminos de la reforma constitucional en el Perú en "Anuario de Derecho Constitucional Latinoamericano", año XI, tomo I, 2005; CARLos BLANCAS Bustaman$\mathrm{TE}$, El control constitucional de la reforma constitucional en "Legal express", núm. 52, abril de 2005. Entre los manuales recientes cf. VíctoR García TOMA, Teoría del Estado y Derecho Constitucional, Palestra editores, Lima 2005, pp. 442-464.

Lima, junio de 2005

Revisado en octubre de 2005 